\title{
Risk Factors for Postoperative Anastomosis Leak After Esophagectomy for Esophageal Cancer
}

\author{
TORU AOYAMA, YOSUKE ATSUMI, KENTARO HARA, HIROSHI TAMAGAWA, \\ AYAKO TAMAGAWA, KEISUKE KOMORI, ITARU HASHIMOTO, YUKIO MAEZAWA, \\ KEISUKE KAZAMA, KAZUKI KANO, MASAAKI MURAKAWA, MASAKATSU NUMATA, \\ TAKASHI OSHIMA, NORIO YUKAWA, MUNETAKA MASUDA and YASUSHI RINO
}

Department of Surgery, Yokohama City University, Yokohama, Japan

\begin{abstract}
Background/Aim: The present study aimed to identify risk factors for anastomosis leak (AL) after esophagectomy for esophageal cancer. Patients and Methods: One-hundred twenty-two patients who underwent esophagectomy for esophageal cancer between 2008 and 2018 were included. The rate of $A L$ was measured based on the definition of leak as adapted from the Surgical Infection Study Group. To identify the risk factors for AL, logistic regression analysis was used. Results: AL was found in 44 of the 122 patients (36.1\%). Among the factors examined, the lymph node dissection status $(p=0.007)$ and preoperative serum albumin level $(p=0.022)$ were significant independent risk factors for $A L$. The incidence of AL was 26.7\% (20 of 75) among patients who received 2-field lymph node dissection and $51.1 \%$ (24 of 47) among those who received 3-field lymph node dissection. The incidence of $A L$ was $29.9 \%$ (23 of 77) in the preoperative serum albumin levels $\geq 4.0 \mathrm{~g} / \mathrm{dl}$ group and $46.7 \%$ (21 of 45 ) in the serum albumin levels $<4.0 \mathrm{~g} / \mathrm{dl}$ group. Conclusion: Lymph node dissection status and preoperative serum albumin levels were risk factors for AL in patients who received esophagectomy for esophageal cancer.
\end{abstract}

Esophageal cancer is a major cause of cancer death worldwide (1). Complete resection is essential for curing esophageal cancer (2-3). However, the morbidity rate after esophagectomy for esophageal cancer ranges from $30 \%$ to $60 \%$, and the morality rate is $1-5 \%$ (4-6). Some studies have shown that the development of anastomosis leak (AL)

This article is freely accessible online.

Correspondence to: Toru Aoyama, Department of Surgery, Yokohama City University, 3-9 Fukuura, Kanazawa-ku, Yokohama 236-0004, Japan. Tel: +81 457872800, e-mail: t-aoyama@lilac.plala.or.jp

Key Words: Esophageal cancer, anastomosis leak, risk factor. increased the risk of disease recurrence and reduced the overall survival in esophageal cancer patients who received esophagectomy (7-8). Therefore, it is important to predict the occurrence of AL before surgery and determine the most appropriate approach to perioperative care.

Recently, the importance of multidisciplinary team efforts, such as oral care and perioperative nutritional care, for preventing AL has been reported $(9,10)$. However, few studies have investigated the risk factors for AL after esophageal cancer surgery (11-16). Thus, further studies are required to identify these risk factors. If they can be clarified, it will be possible to determine the appropriate indications of oral care and perioperative nutritional care and to select suitable surgical procedures considering the balance between risks and benefits.

The aim of the present study was to identify risk factors for AL after esophagectomy for esophageal cancer.

\section{Patients and Methods}

Patients. The patients were selected from the medical records of consecutive patients who received curative resection for esophageal cancer at Yokohama City University from 2005 to 2018. The inclusion criteria were as follows: 1) histologically proven primary esophageal adenocarcinoma or squamous cell carcinoma, 2) clinical stage IB to III (excluding T4) according to the 7th edition of the tumor-node-metastasis classification, and 3) complete (R0) resection of the esophageal cancer with radical lymph node dissection. Patients who had undergone R2 or R1 resection were excluded from the study.

Surgical procedure. Our subtotal esophagectomy defined as subtotal esophagectomy with resection of both lesser curve and subcardial area of the stomach. Greater curvature tube was used for reconstruction. In addition, cervical anastomosis was performed in all cases. In principle, two-field lymph node dissection is indicated when tumors are located at the middle thoracic to lower thoracic esophagus, while three-field dissection is applied for upper thoracic tumors.

Perioperative care. The patients were managed using the same perioperative care (17). Briefly, cefazolin $(1 \mathrm{~g})$ was administered 30 min before the surgical incision, every $3 \mathrm{~h}$ during surgery, and at a 
Table I. Definition of leak as adapted from the Surgical Infection Study Group.

\begin{tabular}{|c|c|c|}
\hline Leak & Definition & Treatment \\
\hline Radiological & No clinical signs & No change in management \\
\hline \multirow[t]{3}{*}{ Clinical minor } & Local inflammation cervical wound X-ray contained leak (thoracic anastomosis) & Drain wound \\
\hline & Elevation of fever, white blood cell, $\mathrm{C}$ reactive protein & Delay oral intake \\
\hline & & Antibiotics \\
\hline Clinical major & Severe disruption on endoscopy Sepsis & CT-guided drainage (Reintervention) \\
\hline Conduit necrosis & Endoscopic confirmation & Reintervention \\
\hline
\end{tabular}

Table II. Clinicopathological data of patients with and without postoperative anatomic leakage.

\begin{tabular}{|c|c|c|c|c|c|c|c|}
\hline \multirow[b]{3}{*}{ Characteristics } & & & \multicolumn{4}{|c|}{ Postoperative anatomic leakage } & \multirow[b]{3}{*}{$p$-Value } \\
\hline & \multicolumn{2}{|c|}{ All cases } & \multicolumn{2}{|c|}{ No $(n=78)$} & \multicolumn{2}{|c|}{ Yes $(n=44)$} & \\
\hline & Number & $\%$ & Number & $\%$ & Number & $\%$ & \\
\hline Age & & & & & & & 0.586 \\
\hline$<68$ years old & 65 & 53.3 & 43 & 55.1 & 22 & 50.0 & \\
\hline$\geq 68$ years old & 57 & 46.7 & 35 & 44.9 & 22 & 50.0 & \\
\hline Gender & & & & & & & 0.492 \\
\hline Male & 106 & 86.9 & 69 & 88.5 & 37 & 84.1 & \\
\hline Female & 16 & 13.1 & 9 & 11.5 & 7 & 15.9 & \\
\hline ASA-PS & & & & & & & 0.073 \\
\hline 1 & 10 & 8.2 & 9 & 11.5 & 1 & 2.3 & \\
\hline $2-3$ & 112 & 91.8 & 69 & 88.5 & 43 & 97.7 & \\
\hline Site of tumor & & & & & & & 0.097 \\
\hline Upper thoracic & 36 & 29.5 & 19 & 24.4 & 17 & 38.6 & \\
\hline Middle-Lower thoracic & 86 & 70.5 & 59 & 75.6 & 27 & 61.4 & \\
\hline Body mass index* & 20.9 & $14.5-29.0$ & 20.8 & $16.1-27.6$ & 21.1 & $14.5-29.0$ & 0.355 \\
\hline Smoking habit & & & & & & & 0.100 \\
\hline Yes & 109 & 89.3 & 67 & 85.9 & 42 & 95.5 & \\
\hline No & 13 & 10.7 & 11 & 14.1 & 2 & 4.5 & \\
\hline Alcohol habit & & & & & & & 0.284 \\
\hline Yes & 112 & 91.8 & 70 & 89.7 & 42 & 95.5 & \\
\hline No & 10 & 8.2 & 8 & 10.3 & 2 & 4.5 & \\
\hline White blood cell* & 6100 & $2800-14000$ & 6300 & $3000-12500$ & 5900 & $2800-14000$ & 0.907 \\
\hline Hemoglobin* & 12.5 & $6.8-16.1$ & 12.5 & $6.8-15.6$ & 12.3 & 8.1-16.1 & 0.940 \\
\hline Albumin* & 4.1 & $1.5-5.0$ & 4.2 & $1.5-5.0$ & 3.9 & $2.3-4.7$ & 0.073 \\
\hline $\mathrm{C}$ reactive protein* & 0.14 & $0.01-8.95$ & 0.09 & $0.01-8.15$ & 0.24 & $0.02-8.95$ & 0.139 \\
\hline
\end{tabular}

ASA-PS: ASA physical status; *median and range.

dose of $2 \mathrm{~g}$ on postoperative day (POD) 2. The patients remained on ventilation overnight. On POD1, ambulation and enteral nutrition were started. On POD5, oral intake was initiated. On POD10, the patients began to eat solid food.

Definition of $A L$. All data were retrospectively retrieved from the medical records. The rate of AL was measured based on the definition of leak as adapted from the Surgical Infection Study Group (Table I) (18).

Definition of habitable alcohol consumption. Patients reported their alcohol consumption and were then categorized into the following
4 groups based on these data: 1) lifelong nondrinkers; 2) mild drinkers (3 to 10 standard drinks/week); 3) moderate drinkers (11 to 20 standard drinks/week); 4) heavy drinkers (>20 standard drinks/week) (19).

Evaluations and statistical analyses. Logistic regression analysis was used in order to predict the risk factors for AL. The chi-square test was used to compare two groups. We used fitted linear regression models in the multivariate analysis. We also used backwards elimination to select a model. $p$-Values of $<0.05$ were considered to indicate statistical significance. The SPSS software package (v11.0 J Win; SPSS, Chicago, IL, USA) was used for all statistical analyses. 
Table III. Surgical and pathological findings of patients with and without postoperative anatomic leakage.

\begin{tabular}{|c|c|c|c|c|c|c|c|}
\hline \multirow[b]{3}{*}{ Characteristics } & & & \multicolumn{4}{|c|}{ Postoperative anatomic leakage } & \multirow[b]{3}{*}{$p$-Value } \\
\hline & \multicolumn{2}{|c|}{ All cases } & \multicolumn{2}{|c|}{ No $(n=)$} & \multicolumn{2}{|c|}{ Yes $(n=)$} & \\
\hline & Number & $\%$ & Number & $\%$ & Number & $\%$ & \\
\hline Neoadjuvant chemotherapy & & & & & & & 0.594 \\
\hline Yes & 51 & 41.8 & 34 & 43.6 & 17 & 38.6 & \\
\hline No & 71 & 58.2 & 44 & 56.4 & 27 & 61.4 & \\
\hline Surgery type & & & & & & & 0.875 \\
\hline Transthoracic & 87 & 71.3 & 56 & 71.8 & 31 & 70.5 & \\
\hline Thoracoscopic & 35 & 28.7 & 22 & 28.2 & 13 & 29.5 & \\
\hline Lymph node dissection & & & & & & & 0.006 \\
\hline Two-field & 75 & 61.5 & 55 & 70.5 & 20 & 45.5 & \\
\hline Three-field & 47 & 38.5 & 23 & 29.5 & 24 & 54.5 & \\
\hline Operative duration & 592 & $259-911$ & 586 & $295-877$ & 623 & $259-911$ & 0.305 \\
\hline Blood loss & 540 & $70-3000$ & 500 & $70-3000$ & 765 & $136-2756$ & 0.059 \\
\hline Blood transfusion & & & & & & & 0.667 \\
\hline Yes & 39 & 32.0 & 26 & 33.3 & 13 & 29.5 & \\
\hline No & 83 & 68.0 & 52 & 66.7 & 31 & 70.5 & \\
\hline Pathological depth of invasion & & & & & & & 0.403 \\
\hline $\mathrm{T} 1$ & 43 & 35.2 & 25 & 32.1 & 18 & 40.9 & \\
\hline $\mathrm{T} 2$ or more & 79 & 64.8 & 53 & 67.9 & 26 & 59.1 & \\
\hline Pathological lymph node status & & & & & & & 0.536 \\
\hline Negative & 62 & 50.8 & 38 & 48.7 & 24 & 54.5 & \\
\hline Positive & 60 & 49.2 & 40 & 51.3 & 20 & 45.5 & \\
\hline Lymph vascular invasion & & & & & & & 0.598 \\
\hline Negative & 38 & 31.1 & 23 & 29.5 & 15 & 34.1 & \\
\hline Positive & 84 & 68.9 & 55 & 70.5 & 29 & 65.9 & \\
\hline
\end{tabular}

Ethics. The present study was conducted in compliance with the 'ethical guidelines for clinical research'. Informed consent for using clinical data without identifying personal information was obtained before surgery from all patients.

\section{Results}

Patient's clinic pathological data. One hundred twenty-two patients received curative surgery for esophageal cancer between 2008 and 2018. Median was 68 years (range $=40$ 82 years). One hundred six patients were male, and 16 patients were female. Forty-four patients were categorized as AL (AL group), and 78 were categorized as without AL (non-AL group). Table II shows the patients background. When comparing patient's clinic pathological data between $\mathrm{AL}$ and non-AL groups, the tumor location was marginally but significantly associated with the incidence of AL $(p=0.097)$, as was the preoperative serum albumin level $(p=0.073)$.

Operative and pathological data. The patients' surgical and pathological data are summarized in Table III. The incidence of three filed lymph node dissection was significantly higher in the AL group than in the non-Al group $(p=0.006)$.
Risk factors for anastomosis leak. The risk factors for AL were analyzed using the preoperative and perioperative factors by logistic regression analysis. Table IV shows the analysis results. Among the factors examined, the lymph node dissection status $(p=0.007)$ and preoperative serum albumin levels $(p=0.022)$ were identified as significant independent risk factors for AL.

The incidence of AL was 26.7\% (20 of 75) among patients who received 2-field lymph node dissection and $51.1 \%$ (24 of 47) among those who received 3-field lymph node dissection. The incidence of AL was $29.9 \%$ (23 of 77) in preoperative serum albumin levels $\geq 4.0 \mathrm{~g} / \mathrm{dl}$ group and $46.7 \%$ (21 of 45 ) in serum albumin levels $<4.0 \mathrm{~g} / \mathrm{dl}$ group.

\section{Discussion}

The aim of the present study was to identify risk factors of AL after esophagectomy for esophageal cancer. The major finding was that the lymph node dissection status and preoperative serum albumin levels were significant risk factors for AL. Therefore, careful attention should be paid to patients with these risk factors when considering esophagectomy for esophageal cancer. 
in vivo $34: 857-862(2020)$

Table IV. Results of univariate and multivariate analyses of risk factors for postoperative anatomic leakage.

\begin{tabular}{|c|c|c|c|c|c|c|}
\hline \multirow[t]{2}{*}{ Characteristics } & \multirow[t]{2}{*}{ Number } & \multicolumn{2}{|c|}{ Univariate analysis } & \multicolumn{3}{|c|}{ Multivariate analysis } \\
\hline & & HR & $p$-Value & HR & $95 \% \mathrm{CI}$ & $p$-Value \\
\hline Age & & & 0.586 & & & \\
\hline$<68$ years old & 65 & 1.000 & & & & \\
\hline$\geq 68$ years old & 57 & 1.228 & $0.586-2.576$ & & & \\
\hline Neoadjuvant chemotherapy & & & 0.595 & & & \\
\hline No & 71 & 1.000 & & & & \\
\hline Yes & 51 & 1.227 & $0.577-2.608$ & & & \\
\hline \multicolumn{7}{|l|}{ Operative type } \\
\hline Transthoracic & 87 & 1.000 & & & & \\
\hline Thoracoscopic & 35 & 1.067 & $0.473-2.409$ & & & \\
\hline Operative duration & & & 0.217 & & & \\
\hline$<590 \mathrm{~min}$ & 59 & 1.000 & & & & \\
\hline$\geq 590 \mathrm{~min}$ & 63 & 1.601 & $0.758-3.380$ & & & \\
\hline Blood loss & & & 0.061 & & & \\
\hline$<540 \mathrm{ml}$ & 61 & 1.000 & & & & \\
\hline$\geq 540 \mathrm{ml}$ & 61 & 2.055 & $0.967-4.369$ & & & \\
\hline Lymph node dissection & & & 0.007 & & & 0.007 \\
\hline Two-field & 75 & 1.000 & & 1.000 & & \\
\hline Three-field & 47 & 2.870 & $1.332-6.182$ & 3.075 & & 928 \\
\hline Smoking habit & & & 0.119 & & & 0.094 \\
\hline No & 13 & 1.000 & & 1.000 & & \\
\hline Yes & 109 & 3.447 & $0.728-16.322$ & 6.031 & 0.7 & .554 \\
\hline Alcohol habit & & & 0.296 & & & \\
\hline No & 10 & 1.000 & & & & \\
\hline Yes & 112 & 2.343 & $0.475-11.566$ & & & \\
\hline Albumin & & & 0.009 & & & 0.022 \\
\hline$\geq 4.0 \mathrm{~g} / \mathrm{dl}$ & 77 & 1.000 & & 1.000 & & \\
\hline$<4.0 \mathrm{~g} / \mathrm{dl}$ & 45 & 2.788 & $1.291-6.022$ & 2.607 & & 924 \\
\hline
\end{tabular}

HR: Hazard ratio; CI: confidence interval.

In the present study, the preoperative serum albumin levels were a significant risk factor in both univariate and multivariate analyses. Indeed, serum albumin levels $<4.0 \mathrm{~g} / \mathrm{dl}$ group had a higher risk of AL than the serum albumin level $<4.0 \mathrm{~g} / \mathrm{dl}$ group. A few previous reports have described the relationship between AL and the perioperative nutritional status in patients who received esophagectomy for esophageal cancer. Gao et al. have evaluated the risk factors of AL in 96 patients who had been diagnosed with esophageal cancer and underwent resection (20). They found that AL occurred in $12.5 \%$ and that a lower prealbumin level was an independent risk factor for AL. These results suggested that a poor preoperative nutritional status was the main risk factor for AL. Previous studies have further reported that the pre- and peri-operative nutrition treatment reduced the surgical complications in patients who had malnutrition $(21,22)$. Perioperative nutrition care might be recommended in patients who had the risk factors to reduce AL.

Previous retrospective studies have reported on the relationship between the lymph node dissection status and the incidence of AL in patients who underwent esophagectomy for esophageal cancer. Igaki et al. have evaluated the oncological outcomes with 2- and 3-field lymph node dissection among 156 patients who had been diagnosed with esophageal cancer and undergone resection (23). Among these 156 patients, 55 (35\%) received 2-field lymph node dissection, and 101 (65\%) received 3 -field lymph node dissection. They found that AL occurred in $55(35 \%)$ patients. Although no significant difference was noted, the incidence of AL tended to be higher in the 3-field lymph node dissection group than in the 2-field lymph node dissection group (39\% vs. $29 \%, p=0.234)$. In addition, a recent meta-analysis including 2 randomized control trials and 18 observational studies with over 7000 patients has shown that 3-field lymph node dissection was associated with a significantly higher incidence of AL than 2field lymph node dissection (relative risk $=1.26 ; 95 \%$ confidence interval $=1.05-1.52 ; p=0.09$ ) (24). Given the present and previous findings, the lymph node dissection status might have some clinical influence on AL in patients who undergo esophagectomy.

An important limitation associated with AL is the lack of consensus regarding the appropriate definition for the 
evaluation of AL. In the present study, AL was reported by individual physicians and was not based on a specific protocol. In addition, we defined AL based on the definition of leak adapted from the Surgical Infection Study Group, and the incidence of AL was $36 \%$. However, the incidence of $\mathrm{AL}$ varies widely and has been reported to range from $0 \%$ to $53 \%$ (25). The main reason for this wide variation is the lack of an optimal definition of AL. For example, Markar et al. have defined AL as a symptomatic disruption of the intrathoracic anastomosis classified as grade III or IV according to the Clavien-Dindo classification (26). A postoperative barium swallow examination was not routinely performed in their study. Andreou et al. have also used the Clavien-Dindo classification, but the definition of AL was not described. A postoperative radio contrast agent swallow examination was routinely performed at day 5 after surgery in their study (27). In addition, a recent systematic literature review of all articles dealing with AL after esophagectomy found only 13 out of 33 publications that included a definition of AL (28). Although the majority of these studies have reported the routine postoperative use of radiographic studies, their timing ranged from 3 to 14 days after the surgery.

There are several potential limitations associated with this study. First, this study was a retrospective, single-center study with a relatively small sample size. Furthermore, this study might have selection bias. Second, a surgical stress marker was not evaluated in the present study. Previous studies have shown that the risk of AL in patients with esophageal cancer is influenced by the general status, nutrition status and immune status. However, we were unable to evaluate these factors in the present study. Given these limitations, the current results should be validated in other series with a larger number of patients.

In conclusion, the lymph node dissection status and preoperative serum albumin levels were risk factors for $\mathrm{AL}$ in patients who underwent curative esophagectomy for esophageal cancer. To avoid AL after esophagectomy for esophageal cancer, it is necessary to carefully plan the surgical strategy, surgical procedure, and perioperative treatment including adjuvant treatment.

\section{Conflicts of Interest}

The Authors declare no conflicts of interest regarding this study.

\section{Authors' Contributions}

TA and YA made substantial contributions to conception and design. TA, KH, HT, AT, KK (Keisuke Komori), YM, KK2 (Kazuki Kano), KK3 (Keisuke Kazama), IH, MM1 (Masaaki Murakawa), MN, TO, NY, MM2 (Munetaka Masuda), and YR made substantial contributions to acquisition of data, or analysis and interpretation of data. TA, KK, YA, HT, AT, KK2 and YR have been involved in drafting the manuscript or revising it critically for important intellectual content. TA, YM, KK3, KH, MM, MN, TO, and MM have given final approval of the version to be published. Each Author should have participated sufficiently in the work to take public responsibility for appropriate portions of the content; and agreed to be accountable for all aspects of the work in ensuring that questions related to the accuracy or integrity of any part of the work are appropriately investigated and resolved. All authors read and approved the final manuscript.

\section{Acknowledgements}

This work was supported, in part, by the nongovernmental organization Yokohama Surgical Research Group, Dr. Masumi Kamachi (Tokyo Shinagawa Hospital), Dr. Ryuji Tominaga (Fukuoka Wajiro Hospital), Dr. Nobuko Yoshiki (Yoshiki Dermatology Clinic Ginza). The Authors express their sincere gratitude to Ms. Akiko Yoshida, Ms. Yuka Maruyama, Ms. Minako Igarashi and Ms. Mariko Yamauchi for their excellent data management in this study.

\section{References}

1 Torre LA, Bray F, Siegel RL, Ferlay J, Lortet-Tieulent J and Jemal A: Global cancer statistics, 2012. CA Cancer J Clin 65: 87-108, 2015. PMID: 25651787. DOI: 10.3322/caac.21262

2 NCCN Clinical Practice Guidelines in Oncology. Available at: https://www.nccn.org/professionals/physician_gls/default.aspx (Last accessed 6/01/2020)

3 Lordick F, Mariette C, Haustermans K, Obermannová R and Arnold D; ESMO Guidelines Committee: Oesophageal cancer: ESMO Clinical Practice Guidelines for diagnosis, treatment and follow-up. Ann Oncol 27: v50-v57, 2016. PMID: 27664261. DOI: $10.1093 /$ annonc/mdw329

4 Biere SS, van Berge Henegouwen MI, Maas KW, Bonavina L, Rosman C, Garcia JR, Gisbertz SS, Klinkenbijl JH, Hollmann MW, de Lange ES, Bonjer HJ, van der Peet DL and Cuesta MA: Minimally invasive versus open oesophagectomy for patients with oesophageal cancer: a multicentre, open-label, randomised controlled trial. Lancet 379: 1887-1892, 2012. PMID: 22552194. DOI: 10.1016/S0140-6736(12)60516-9

5 Mantziari S, Hübner M, Demartines N and Schäfer M: Impact of preoperative risk factors on morbidity after esophagectomy: is there room for improvement? World J Surg 38: 2882-2890, 2014. PMID: 25002245. DOI: 10.1007/s00268-014-2686-9

6 Dhungel B, Diggs BS, Hunter JG, Sheppard BC, Vetto JT and Dolan JP: Patient and peri-operative predictors of morbidity and mortality after esophagectomy: American College of Surgeons National Surgical Quality Improvement Program (ACS-NSQIP), 2005-2008. J Gastrointest Surg 14: 1492-1501, 2010. PMID: 20824375. DOI: 10.1007/s11605-010-1328-2

7 Junemann-Ramirez M, Awan MY, Khan ZM and Rahamim JS: Anastomosis leakage post-esophagogastrectomy for esophageal carcinoma: retrospective analysis of predictive factors, management and influence on long-term survival in a high volume centre. Eur J Cardiothorac Surg 27: 3-7, 2005. PMID: 15621463. DOI: $10.1016 /$ j.ejcts.2004.09.018

8 Rutegård M, Lagergren P, Rouvelas I and Lagergren J: Intrathoracic anastomosis leakage and mortality after esophageal cancer resection: a population-based study. Ann Surg Oncol 19: 99-103, 2012. PMID: 21769467. DOI: 10.1245/s10434-011-1926-6 
9 Bolton JS, Conway WC and Abbas AE: Planned delay of oral intake after esophagectomy reduces the cervical anastomotic leak rate and hospital length of stay. J Gastrointest Surg 18: 304309, 2014. PMID: 24002761. DOI: 10.1007/s11605-013-2322-2

10 Weijs TJ, Berkelmans GH, Nieuwenhuijzen GA, Dolmans AC, Kouwenhoven EA, Rosman C, Ruurda JP, van Workum F, van Det MJ, Silva Corten LC, van Hillegersberg R and Luyer MD: Immediate postoperative oral nutrition following esophagectomy: A multicenter clinical trial. Ann Thorac Surg 102: 1141-1148, 2016. PMID: 27324526. DOI: 10.1016/j.athoracsur.2016.04.067

11 Kita T, Mammoto $\mathrm{T}$ and Kishi Y: Fluid management and postoperative respiratory disturbances in patients with transthoracic esophagectomy for carcinoma. J Clin Anesth 14: 252-256, 2002. PMID: 12088806. DOI: 10.1016/s0952-8180 (02)00352-5

12 Asteriou C, Barbetakis N, Lalountas M, Kleontas A and Tsilikas $\mathrm{C}$ : Modified pleural tenting for prevention of anastomotic leak after Ivor Lewis esophagogastrectomy. Ann Surg Oncol 18: 37373742, 2011. PMID: 21674267. DOI: 10.1245/s10434-011-1835-8

13 Gronnier C, Tréchot B, Duhamel A, Mabrut JY, Bail JP and Carrere $\mathrm{N}$ : Impact of neoadjuvant chemoradiotherapy on postoperative outcomes after esophageal cancer resection: results of a European multicenter study. Ann Surg 260: 764-770, 2014. PMID: 25379847. DOI: 10.1097/SLA.0000000000000955

14 Tapias LF, Muniappan A, Wright CD, Gaissert HA, Wain JC, Morse CR, Donahue DM, Mathisen DJ and Lanuti M: Short and long-term outcomes after esophagectomy for cancer in elderly patients. Ann Thorac Surg 95: 1741-1748, 2013. PMID: 23500043. DOI: 10.1016/j.athoracsur.2013.01.084

15 Wouters MW, Gooiker GA, van Sandick JW and Tollenaar RA: The volume-outcome relation in the surgical treatment of esophageal cancer: a systematic review and meta-analysis. Cancer 118: 1754-1763, 2012. PMID: 22009562. DOI: 10.1002/cncr.26383

16 Markar SR, Arya S, Karthikesalingam A and Hanna GB: Technical factors that affect anastomotic integrity following esophagectomy: systematic review and meta-analysis. Ann Surg Oncol 20: 4274-4281, 2013. PMID: 23943033. DOI: 10.1245/ s10434-013-3189-x

17 Kano K, Aoyama T, Yoshikawa T, Maezawa Y, Nakajima T, Hayashi T, Yamada T, Sato T, Oshima T, Rino Y, Masuda M, Cho $\mathrm{H}$ and Ogata $\mathrm{T}$ : The negative survival impact of infectious complications after surgery is canceled out by the response of neoadjuvant chemotherapy in patients with esophageal cancer. Ann Surg Oncol 25: 2034-2043, 2018. PMID: 29748890. DOI: 10.1245/s 10434-018-6504-8

18 Lerut T, Coosemans W, Decker G, De Leyn P, Nafteux P and van Raemdonck D: Anastomotic complications after esophagectomy. Dig Surg 19: 92-98, 2002. PMID: 11978992. DOI: 10.1159/ 000052018

19 Voskoboinik A, Costello BT, Kalman E, Prabhu S, Sugumar H, Wong G, Nalliah C, Ling LH, McLellan A, Hettige T, Springer F, La Gerche A, Kalman JM, Taylor AJ and Kistler PM: Regular alcohol consumption is associated with impaired atrial mechanical function in the atrial fibrillation population: A cross-sectional MRI-based study. JACC Clin Electrophysiol 4: 1451-1459, 2018. PMID: 30466852. DOI: 10.1016/j.jacep. 2018.07.010
20 Gao C, Xu G, Wang C and Wang D: Evaluation of preoperative risk factors and postoperative indicators for anastomotic leak of minimally invasive McKeown esophagectomy: a single-center retrospective analysis. J Cardiothorac Surg 14: 46, 2019. PMID: 30819240. DOI: 10.1186/s13019-019-0864-4

21 Gianotti L, Braga M, Nespoli L, Radaelli G, Beneduce A and Di Carlo V: A randomized controlled trial of preoperative oral supplementation with a specialized diet in patients with gastrointestinal cancer. Gastroenterology 122: 1763-1770, 2002. PMID: 12055582. DOI: 10.1053/gast.2002.33587

22 Akbarshahi H, Andersson B, Nordén M and Andersson R: Perioperative nutrition in elective gastrointestinal surgerypotential for improvement? Dig Surg 25: 165-174, 2008. PMID: 18515968. DOI: $10.1159 / 000136478$

23 Igaki H, Tachimori Y and Kato H: Improved survival for patients with upper and/or middle mediastinal lymph node metastasis of squamous cell carcinoma of the lower thoracic esophagus treated with 3-field dissection. Ann Surg 239: 483-490, 2004. PMID: 15024309. DOI: 10.1097/01.sla.0000118562.97742.29

24 Ma GW, Situ DR, Ma QL, Long H, Zhang LJ, Lin P and Rong TH: Three-field vs two-field lymph node dissection for esophageal cancer: a meta-analysis. World J Gastroenterol 20: 18022-18030, 2014. PMID: 25548502. DOI: 10.3748/wjg.v20. i47.18022

25 Blencowe NS, Strong S, McNair AG, Brookes ST, Crosby T, Griffin SM and Blazeby JM: Reporting of short-term clinical outcomes after esophagectomy: a systematic review. Ann Surg 255: 658-666, 2012. PMID: 22395090. DOI: 10.1097/SLA. 0b013e3182480a6a

26 Andreou A, Biebl M, Dadras M, Struecker B, Sauer IM, ThussPatience PC, Chopra S, Fikatas P, Bahra M, Seehofer D, Pratschke $\mathrm{J}$ and Schmidt SC: Anastomosis leak predicts diminished long-term survival after resection for gastric and esophageal cancer. Surgery 160: 191-203, 2016. PMID: 27067160. DOI: $10.1016 /$ j.surg.2016.02.020

27 Markar S, Gronnier C, Duhamel A, Mabrut JY, Bail JP, Carrere $\mathrm{N}$, Lefevre JH, Brigand C, Vaillant JC, Adham M, Msika S, Demartines N, Nakadi IE, Meunier B, Collet D and Mariette C; FREGAT (French Eso-Gastric Tumors) working group, FRENCH (Fédération de Recherche EN CHirurgie), and AFC (Association Française de Chirurgie): The impact of severe anastomosis leak on long-term survival and cancer recurrence after surgical resection for esophageal malignancy. Ann Surg 262: 972-980, 2015. PMID: 26469952. DOI: 10.1097/SLA. 0000000000001011

28 Bruce J, Krukowski H, Al-Khairy G, Russell EM and Park GM: Systematic review of the definition and measurement of anastomotic leak after gastrointestinal surgery. Br J Surg 88: 1157-1168, 2001. PMID: 11531861. DOI: 10.1046/j.00071323.2001.01829.x
Received December 11, 2019

Revised January 3, 2020

Accepted January 7, 2020 